\title{
Tender method for technically complex construction works of public
}

\author{
A. Kazaz ${ }^{1 *}$, E. Erkovan ${ }^{2}$ and Ş. Adıgüzel Ist11 ${ }^{1}$ \\ ${ }^{1}$ University of Akdeniz, Civil Engineering Department, Antalya, Turkey \\ ${ }^{2}$ General Directorate of ASAT, Gazipaşa Branch Office, Antalya, Turkey
}

\begin{abstract}
As a reflection of the development of technology day by day, technically more complex and unique solutions emerge in construction projects. As a result, these projects need to be built by public institutions. In general, public institutions with experience in providing technical pre-defined projects are insufficient to demonstrate the necessary flexibility and reaction in the face of this new situation. For this reason, public institutions prefer projects that they have already experienced and know their technical characteristics instead of those projects that might provide their needs better and more effectively. Within the scope of public procurement law No. 4734 which regulates the purchases of all kinds of goods, services and construction works belonging to the public, the effective and correct implementation of Article 21 (e) arranged for the purchase of construction works with original and complex technical features is high importance for the efficient use of public resources. In this study, it is aimed to show the advantages of the tender method to be used for the procurement of original and complex construction works to public institutions. First of all, the existing tender methods will be examined in briefly, and information about Article 21 (e) of the public procurement law will be provided and the benefits of the method will be presented in the light of a sample application.
\end{abstract}

\section{Keywords}

Technically complex construction works; Article 21(e); Bargaining procedure; Public procurement law

Received: 27 February 2019; Accepted: 21 March 2019

ISSN: 2630-5771 (online) @ 2019 Golden Light Publishing All rights reserved.

\section{Introduction}

The purchase of goods, services and construction works requested for the fulfillment of public needs is realized by the tender method. The principles and procedures to be applied in the tenders of public institutions and organizations that are currently using public resources are determined by the public procurement law No. 4734, which came into force on $01 / 01 / 2003$.

The success of any construction project can be achieved by realizing the three main objectives of time, cost and quality at the optimum point. Therefore, the need for efficient use of public resources with the provision of these elements in the procurement of public works projects will be fulfilled. With the development of technology, the construction projects needed by the public are becoming similarly authentic and technically complex.

With existing public procurement methods, public institutions with experience in procurement of previously technically defined construction projects, whose characteristics are known, are insufficient to realize these emerging complex and technically unambiguous construction works. In order to tendering such projects by public 
institutions, it is of high importance that the method established in Article 21(e) of the Public Procurement Law No. 4734 is fully understood and the implementation of the right projects is of high importance in the fulfillment of the elements such as cost and quality mentioned above.

As a result of the literature survey, it has been observed that many studies were carried out about the public procurement law given below. Camparison with EU public procurement directive 2004/18/EC and procurement law no.4734 in determination of economically most advantageus bid [1], Examination and assessment of tendering procedures included in the public procurement law in respect to effective utilisation of public resources [2], The analysis of factors effecting the low limit values in infrastructer tenders [3], An analysis of public procurement procedures in Turkey in the context of corruption risk. [4], Tenders Construction Problems and Solutions [5]. Although all of these above mentioned and other studies are generally about general issues such as public procurement methods and problems encountered, no specific sample has been found on the implementation of Article 21 (e). Therefore, it is envisaged that the implementation of Article 21 (e) of this study will be a useful guide to public administrations as it shows the benefits in the light of an exemplary application.

\section{Tender methods}

According to No: 4734 public procurement law Article 18. It is stated that one of the three tender procedures can be applied in the procurement of goods or services by the administrations and in the procurement of construction works. These tender methods are open tender procedure, restricted procedure and bargaining procedure among certain bidders. These procedures are defined as follows in public procurement law No. 4734. [6]

\subsection{Open procedure}

Article 19- Open procedure is a procedure where all tenderers may submit their tenders.

\subsection{Restricted procedure}

Article 20- Restricted procedure is a procedure in which tenderers who are invited following prequalification by the contracting authority, can submit their tenders. Procurement of goods, services or works may be conducted by restricted procedure where open procedure is not applicable as the nature of the subject necessitates speciality and/or high technology and in procurement of works where estimated costs exceed the half of threshold value.

Pre-qualification evaluation shall be carried out in accordance with the qualification criteria, which are established pursuant to Article 10 and specified in the pre-qualification documents and in the prequalification notices. Those who fail to meet the minimum requirements specified in these documents shall not be accepted as qualified. Provided that it is stated in prequalification notice and document, all or a certain number of the tenderers who have been considered as qualified from those who have been listed by ranking according to specified criteria set forth in the document may be invited to submit their tenders.

The candidates who have not been invited to submit tenders shall be informed in writing about the reasons. The procurement shall be concluded after the evaluation of the tenders in accordance with the evaluation criteria that are designed in accordance with Article 40 in a way to avoid any impediment to competition depending on the nature of the work and that are specified in the tender documents and in the letter of invitation. In case the number of tenderers that can be invited to submit tenders is less than five or the number of tenderers that submit tenders is less than three, the procurement shall be cancelled.

In case of the cancellation of procurement due to the number of tenderers being less than three, the procurement proceedings may be concluded by reviewing the tender documents and eliminating the deficiencies and errors, if any; and by re-inviting all pre-qualified tenderers. 


\subsection{Open procedure}

Article 21- Bargaining procedure may be applied, where;

a) no tender is submitted in open or restricted procedures,

b) it is inevitable to conduct the tender procedures immediately, due to unexpected and unforeseen events such as natural disasters, epidemics, risk of losing lives or properties or events that could not be predicted by the contracting authority,

c) it is inevitable to conduct the tender procedures immediately, due to occurrence of specific events relating to defence and security,

d) the procurement is of a character requiring a research and development process, and not subject to mass production,

e) due to specific and complex characteristics of the works, goods or services to be procured, it is impossible to define the technical and financial aspects clearly,

f) product good, material and services procurements by contracting authorities with estimated costs of up to fifty billion Turkish Liras.

\section{Construction works in public procurement}

According to the statistics for public purchases in 2017 , the monetary rate of construction works in all public purchases was $62.31 \%$. A total of 210.299.779.100,00-TL amount of purchase made by the administrations under the Law No. 4734 in $2017,131.045 .9991 .000,00-T L$ portion belongs to construction works. As can be seen from the Table 1 given below, which shows the statistics for public procurement in the last 10 years, the monetary ratios of construction works within the scope of public procurement are showing an increasing trend. [8]

And also, in study of Emek and Acar [9] shows that the share of public construction expenditures constituted around $17-20 \%$ of total public expenditures over the period of 2008-2013
Table 1. Monetary ratio of construction works within the scope of all public procurement

\begin{tabular}{cc}
\hline Year & Monetary ratio of construction works \\
\hline 2017 & $62,31 \%$ \\
2016 & $51,20 \%$ \\
2015 & $41,96 \%$ \\
2014 & $40,50 \%$ \\
2013 & $59,48 \%$ \\
2012 & $57,16 \%$ \\
2011 & $51,52 \%$ \\
2010 & $34,47 \%$ \\
2009 & $37,06 \%$ \\
2008 & $38,20 \%$ \\
\hline
\end{tabular}

As can be seen above, construction works in public procurement have a significant monetary rate. For this reason, determining and implementing the right method in the tender of construction works is of great importance in terms of efficient and effective use of public resources.

\section{Procurement of original and complex construction works}

The construction was built mainly by government agencies and institutions have made the purchase previously generally known by the technical details of such projects consist of buildings, roads, dams, bridges, sewerage network etc. However, in parallel with the developing technology, new techniques and solutions are emerging in the construction business, it is seen that the public institutions have difficulty in obtaining these new solutions because they do not know their technical and financial characteristics as well as being original and complex, so they are not directed to such solutions. Therefore, the solutions that are more efficient, cost-effective, new and up-to-date technology needed by the public sector could not be selected. As a result; The principle of efficient and effective use of public resources has not been implemented. Due to the fact that solutions with original and complex technical features are not experienced in advance, they are hesitant to apply 
them by public institutions and perhaps prefer classical solutions rather than better solutions because of the fear of experiencing legal distress due to the risks or negativities that may arise in the implementation of the project in the future. For the solution of this negative situation, the regulation in Article 21 (e) of the Public Procurement Law No. 4734 has been presented as a method of purchase to public institutions.

\section{Implementation of article 21 (e) of the bargain procedure}

The process of procurement of the works to be performed by public institutions and organizations pursuant to Article 21(e) of public procurement law no 4734 shall be as follows "type administrative specification to be applied for construction works which are being procured in accordance with the provisions of Article 21 (a), (d), (f) of the law no 4734".they are required to do this in the order indicated in the article 3.3. and shown below. [7]

3.3. The following procedure is applied in this tender:

a) Qualification assessment.

b) Taking initial proposals without price.

c) To make technical meeting on the first proposals without price.

ç) Clarification of technical specifications.

d) To determine the tenderers who can meet the technical specifications.

e) Taking price proposals.

f) Taking the latest written price proposals.

g) Finalization of tender by evaluation of proposals.

\subsection{Qualification assessment}

Within the scope of the qualification criteria specified in the tender announcement by the administration, the tender envelope and the qualification documents submitted by the bidders are evaulated to the article 20 and article 21 of the type administrative specification. The tenderers who meet the required qualification criteria as a result of the evaluation are considered as sufficient. The tenderers who have determined that they do not fulfill the qualification criteria are not accepted as sufficient. The tenderers who are determined to be qualified shall be asked to submit their initial bids which does not include price but these bids contains technical details of the project and the methods of realization.

\subsection{Taking initial proposals without price}

During the period determined by the tender commission, tenderers submit their initial bids, which do not include the price, on matters such as technical details of the tender and the methods of realization.

\subsection{Making technical meetings on initial proposals without price}

At this stage, each tenderer submitting their initial bids without the price of the tender commission is interviewed on the methods and solutions to meet the needs of the Administration in the most appropriate manner. In this way, the technical details are obtained by the tenderers about the need which is not fully known by the administration.

\subsection{Clarification of technical specifications}

In the light of the information obtained as a result of the interviews on the technical solutions offered by the tenderers by the tender commission, the conditions of the technical specifications in the form of frames at the beginning are clarified.

\subsection{To determine the tenderers who can meet the technical specifications}

In accordance with the technical specification, the revised technical proposals submitted by the bidders are examined and the bidders who can meet the specifications are determined.

\subsection{Taking price proposals}

As a result of the technical interviews, bidders who can meet the conditions are asked to submit their bids by the date and time determined by the tender commission, including price proposals based on the technical specifications. Bids submitted to the administration by the date and time determined by the tender commission shall be examined according to the order of submission. Price offers are 
evaluated within the framework of the points specified in the article 34 and article 35 of type administrative specifications and current offers are determined. Non-valid offers are excluded.

\subsection{Taking the latest written price proposals}

As a result of the evaluation made by the tender commission, bidders are asked to submit their latest written price proposals, not exceeding the initial price offers and based on the tender decision. Tenderers submit their bids to the tender commission on the date and time notified to them.

\subsection{Finalization of tender by evaluation of proposals}

The tender commission evaluates the latest price proposals submitted by tenderers within the framework of the points specified in the articles 37 , $38,39,40$ and 40 of the type administrative specification and concludes the tender by determining the most advantageous offer economically.

Article 21 (e) of the bargaining procedure described above is increasingly used by public institutions and organizations as a method of purchase. According to the tender statistics published by the Public Procurement Authority, although the rates of article 21 (e) of the bargaining procedure in the procurement of construction works by the administrations are very small, it is observed that this rate is increasing every year which can be seen from Table 2.

For this reason, it is important for public institutions to use this method effectively and correctly so that they can implement original and technically complex projects.

Table 2. The monetary rate of a negotiated method 21(e) within all construction purchases

\begin{tabular}{clll}
\hline Year & $\begin{array}{c}\text { Monetary amount } \\
\text { of construction } \\
\text { works (TL) }\end{array}$ & $\begin{array}{c}\text { The monetary } \\
\text { amount of } \\
\text { Article 21 (E) of } \\
\text { the bargain } \\
\text { procedure (TL) }\end{array}$ & Rate \\
\hline 2017 & $131.045 .991 .000,00$ & $2.733 .509 .000,00$ & $2,09 \%$ \\
2016 & $79.693 .980 .000,00$ & $316.618 .000,00$ & $0,40 \%$ \\
2015 & $53.808 .006 .000,00$ & $139.629 .000,00$ & $0,26 \%$ \\
2014 & $39.453 .618 .000,00$ & $5.900 .300,00$ & $0,01 \%$ \\
\hline
\end{tabular}

\section{Gazipaşa wastewater treatment plant as a study case}

County of Gazipaşa is $180 \mathrm{~km}$ from Antalya in the east. It is the district on the border of Mersin province. The location of Gazipaşa City is shown in Fig. 1. After the completion of the sewage network construction of the district in 2009, the municipality of Gazipaşa initiated the necessary works for the construction of wastewater treatment plant. Gazipaşa municipality examined different types of wastewater treatment facilities in Kumluca district of Antalya province and Bodrum district of Muğla province and obtained the necessary construction and operation information about these facilities. After the evaluation phase, the municipality administration decided to choose membrane bio reactor (MBR) wastewater treatment plant instead of the extended aeration activated sludge biological wastewater treatment plant proposed by the General Directorate of Iller Bank which is providing technical support and credit in this regard. It was envisaged that the construction of MBR wastewater treatment plant, which was the only example in Turkey at that time in the town of Konacik in Bodrum county, would provide the needs in a much better way.

The General Directorate of Iller Bank was against the construction of the MBR plant at the beginning. They believed that MBR technology is new in the world. And there was only one sample in Turkey. They thought that changing of membrane units used in the MBR plant will be very expensive in case of possible failure. But municipality administration insisted on the selection of the MBR system by taking into account the benefits it will provide, and in this respect, it was decided to jointly tender the facility by convincing the General Directorate of Iller Bank. Due to the fact that MBR wastewater treatment plants have to be designed according to the membrane model to be selected due to the structure, an application project could not be carried out by the administration. For this reason, it has been concluded that the tender should be awarded in the form of project + construction + operation, as well as in accordance with Article 21 (e) of the 


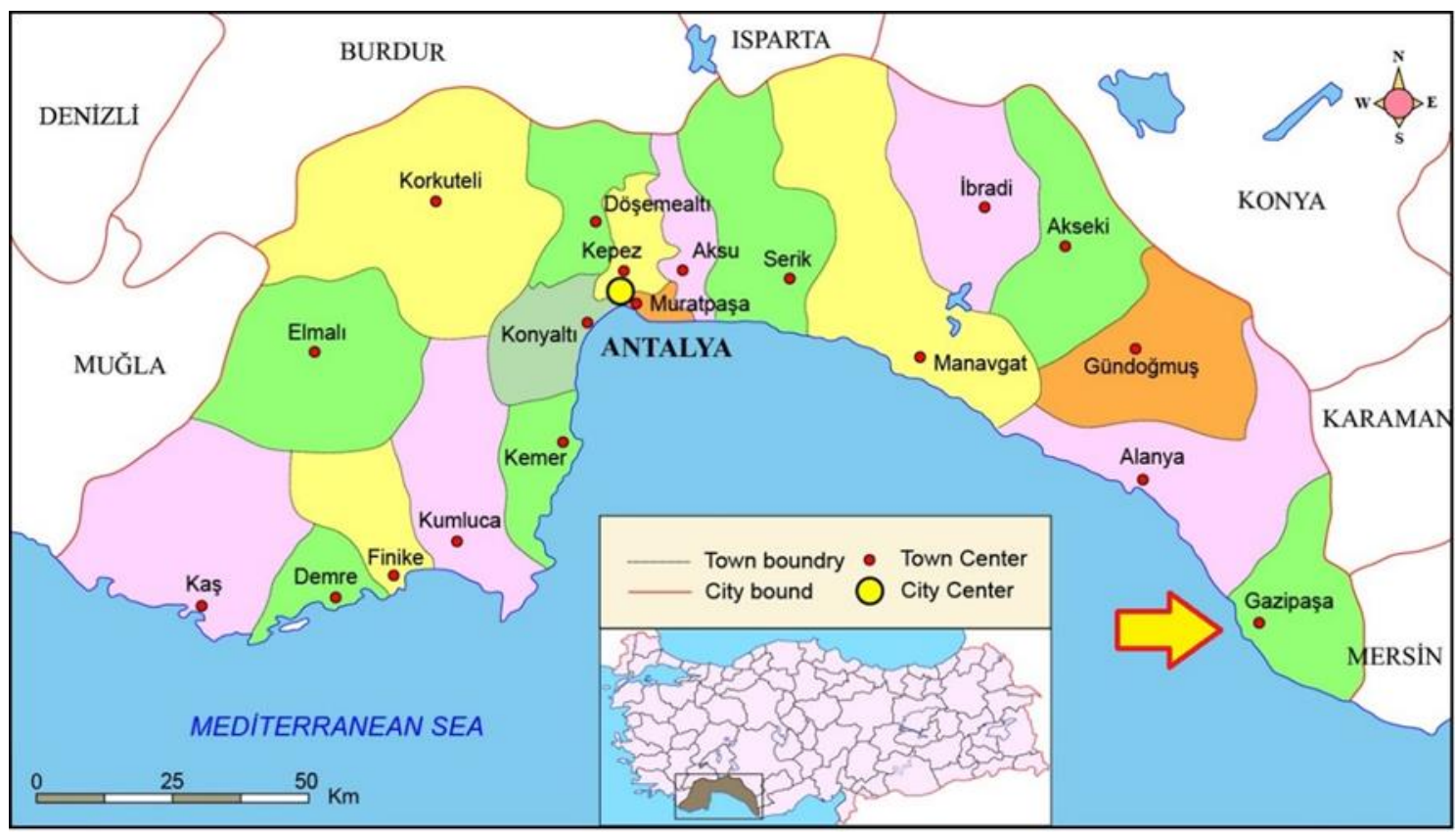

Fig. 1. The location of Gazipaşa City (Source: http://cografyaharita.com/haritalarim/41-maf-of-antalya.png)

bargaining procedure due to its unique and technically complexity.

The tender announcement was made on $15 / 04 / 2010$ by Gazipaşa Municipality and the General Directorate of the Iller Bank. 15 candidate companies participated in the tender held at 14:00 on $06 / 05 / 2010$ with the tender registration number 2010/43061. It has been determined that 14 candidates from these companies are sufficient and it has been stated that they should submit their technical proposals by 14:00 on 31/05/2010 at the latest and that each candidate and these technical proposals will be discussed separately. On 31/05/2010, a total of 12 candidates submitted their technical proposals. The tender commission conducted individual interviews with all bidders on the technical solutions they offer and the technical specifications were clarified by the administration as a result of the interviews. The tenderers have been asked to submit their technical proposals according to the technical specifications that have been announced until 14:00 on 26/10/2010. On this date, technical proposals were submitted by 10 tenderers, and as a result of the review conducted by the tender commission, technical proposals of 6 tenderers were determined to be sufficient. Sufficient bidders have been asked to submit their price offers. 6 bidders submitted the price proposals on the requested date, and as a result of the review by the tender commission, it was determined that the price proposals of 3 tenderers are valid. It's been asked the latest price proposals from 3 bidders. The lowest bidder has been determined and the tender has been left on the this bidder. The tender process was concluded by signing a contract with the Contractor on 22/02/2011 with the conclusion of the objections made by the bidders during the evaluation phase.

\section{Benefits of choosing a high-tech wastewater treatment plant}

Although Gazipaşa municipality is a relatively small district municipality with this construction project, it has chosen high-tech MBR waste water treatment plant, instead of the classical extended aeration activated sludge waste treatment plant known for its technical specifications proposed by the General Directorate of Iller Bank which is one of the most specialized technical institutions in the country on waste water treatment plants. With this 
selection, the administration was able to establish its waste treatment plant in a field of less than $50 \%$ compared to the classical system and thus gained half of its valuable land. Gained land can be shown in Fig. 2. Again, the output water treatment parameters are much lower compared to a conventional treatment plant. The Clarity of the treated water can be seen in Fig. 3. With this facility, a very small amount of treatment sludge has been produced compared to a conventional plant, so there has been a significant advantage in the disposal of treatment sludge. As the treated water is in the quality of irrigation water, it is possible to use this opportunity in the future. The realization of all these benefits mentioned above has been possible by the realization of the MBR treatment plant, which is an original and complex, high-tech construction project. Membrane units can be seen in Fig. 4.

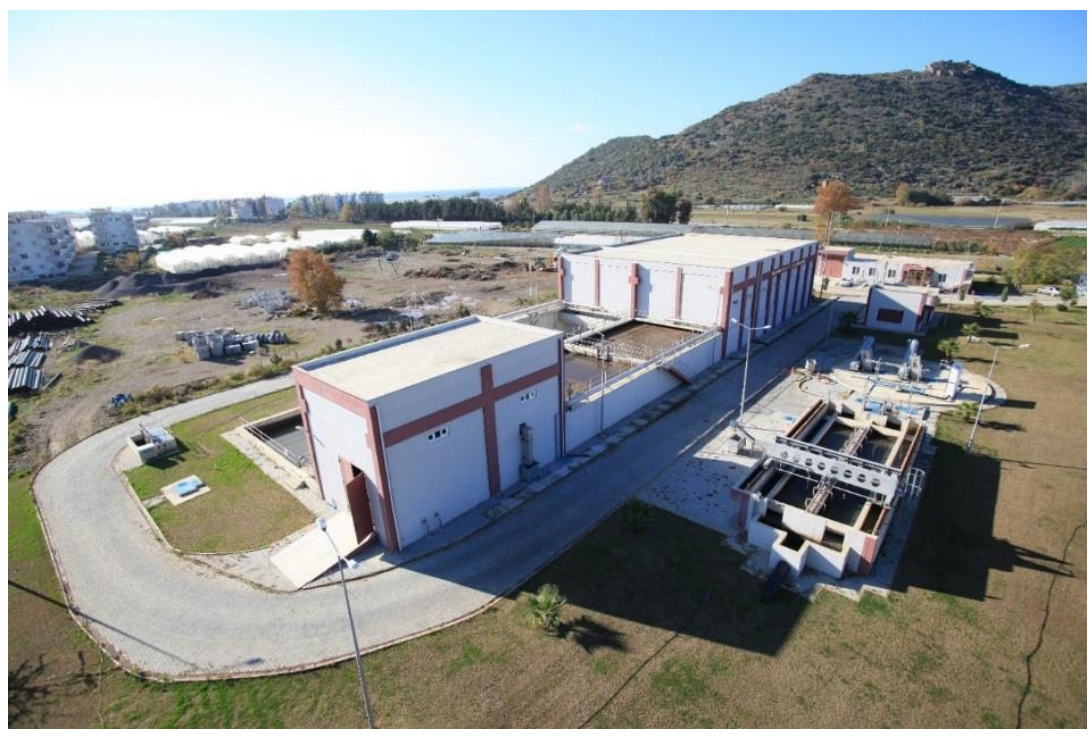

Fig. 2. The gained land next to Gazipaşa Wastewater Treatment Plant

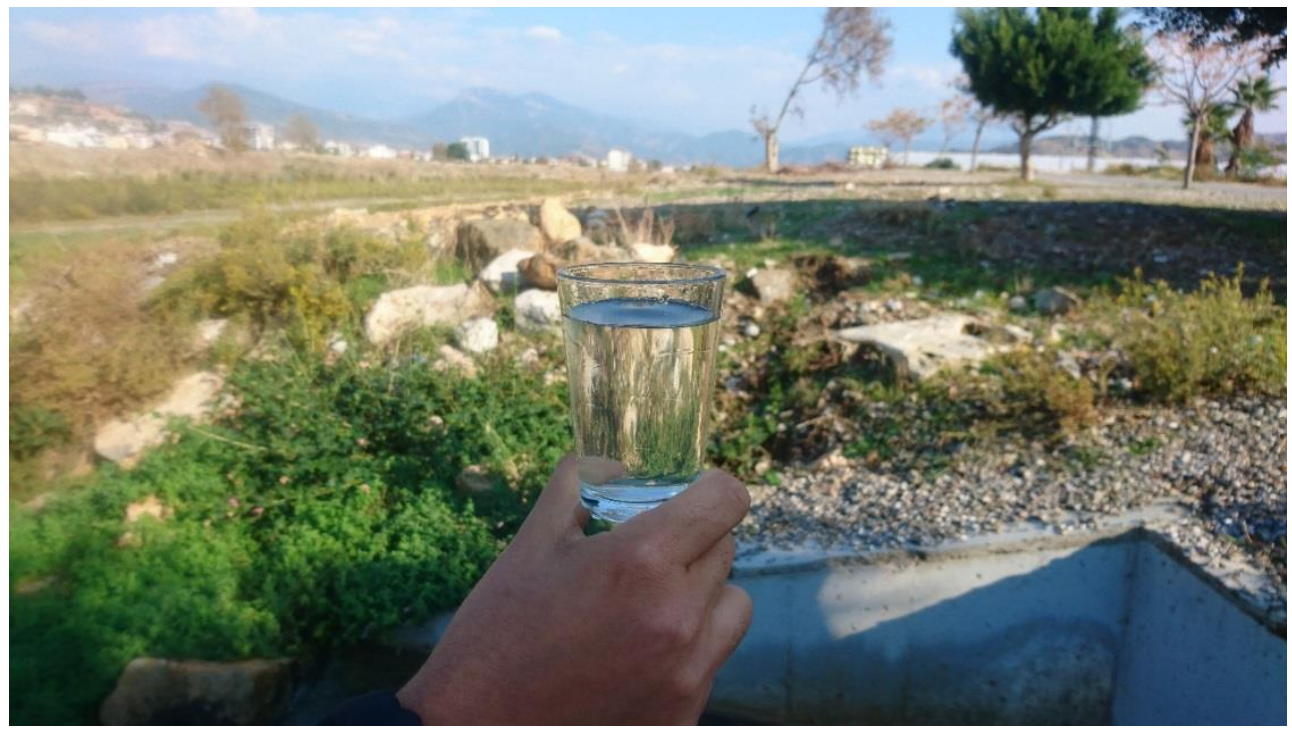

Fig. 3. The clarity of the treated water 


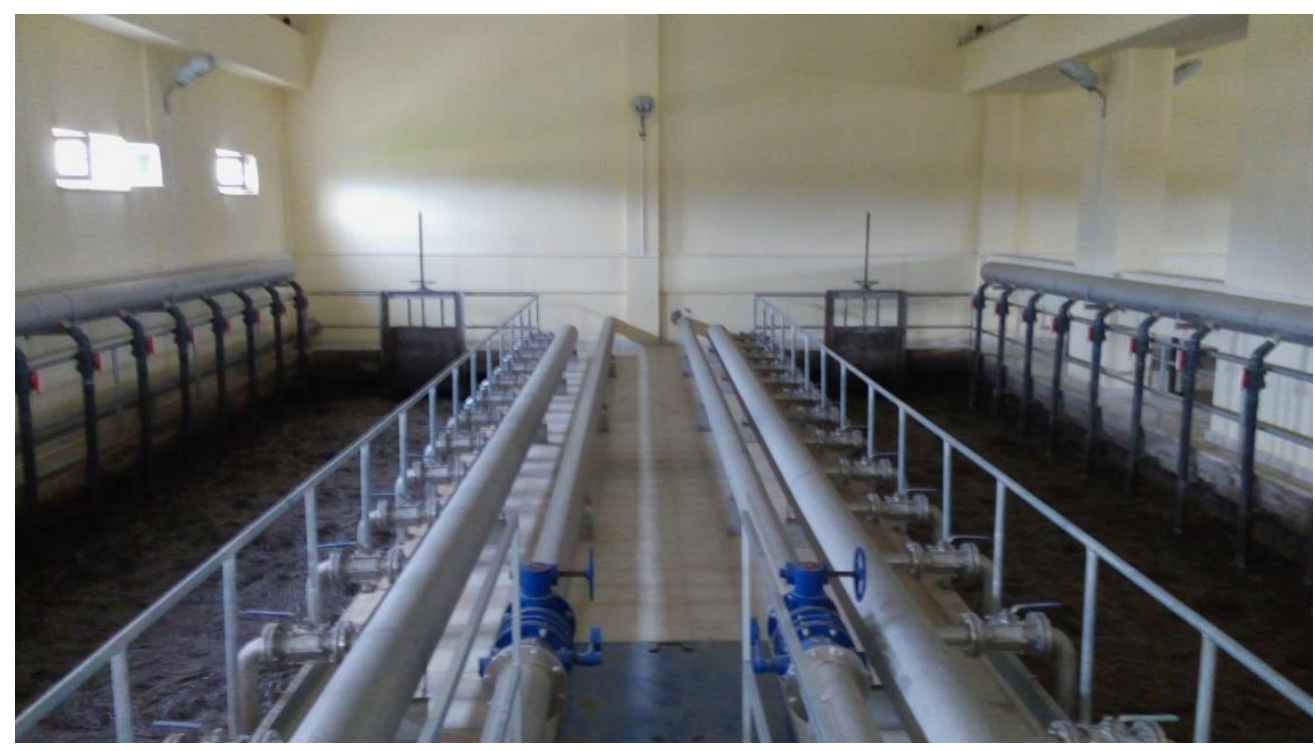

Fig. 4. Membrane units of Gazipaşa Wastewater Treatment Plant

\section{Conclusion}

As a result, administrations should not hesitate to implement these projects that meet in the best way the needs of theirs. Even if they are unique and technically complex projects. The most appropriate method for realization of such projects is the implementation of Article 21 (e) of public procurement law No. 4734.

1) The most important difference between the other tender methods of Article 21 (e) is that the tender commission negotiates with all bidders faceto-face with the technical solutions they offer and clarifies the technical characteristics of the work that is not fully apparent at the beginning. For this reason, in the selection of the technical expert members of the tender commission, selection of the personnel with sufficient knowledge and experience that can clarify technical specifications in the light of technical solutions coming from companies as a result of these technical interviews is critical.

In the event that such personnel are not present in the administration at all or sufficiently, it is appropriate to appoint the personnel in other administrations that have been involved in similar projects.

2) In realization of projects which have not been experienced before and whose technical specifications are not fully defined, it is seen that tender of the drawings of the project, construction and operation works as a single project will be much more reliable in terms of the administration. The fact that the drawings of the project, construction and operation cases are linked together means that the responsibility is assumed by a single contractor as a result of these three processes carried out by the same contractor and the risk is reduced in terms of the administration.

\section{References}

[1] Akçay C, Karakaş A, Sayın B, Manisalı E (2012) Camparison with EU public procurement directive 2004/18/EC and procurement law no.4734 in determination of economically most advantageus bid. e-Journal of New World Sciences Academy 7 (1): 1-340.

[2] Ertaş RC. Examination and assessment of tendering procedures included in the public procurement law in respect to effective utilisation of public resources. Post Graduate Thesis, Gazi University, 2010

[3] Gencer H, Cankatar MA (2012) The analysis of factors effecting the low limit values in infrastructer tenders (According to the public procurement law). e-Journal of New World Sciences Academy 7(1): 129-140. 
[4] Özer B, Miynat M (2016) An analysis of public procurement procedures in Turkey in the context of corruption risk. CBU Journal of Social Sciences 16 (2): 13-21.

[5] Solak A (2013) Tenders Construction Problems and Solutions. KSU Journal of Engineering Sciences 12 (2): 21-50.

[6] Public Procurement Law No. 4734 (2003) http://www.ihale.gov.tr/DokumanDownload.aspx? DokumanID=1079. Date of access: 24.02.2019

[7] Type administrative specification which will be applied in construction works that awarded by bargaining procedure according to the subparagraphs (a), (d), (e) of Article 21 of the Law No. $4734 \quad$ (2003) http://www.ihale.gov.tr/DokumanDownload.aspx? DokumanID=937. Date of access: 24.02.2019

[8] http://ihale.gov.tr/ihale_istatistikleri-45-1.html Date of access: 24.02.2019

[9] Emek U, Acar M. Public procurement in infrastructre: the case of Turkey. In: MungiuPippidi A. (ed) Government Favouritism in Europe: The Anticorruption Report, Barbara Budrich Publishers, 2015, pp.84-96. 